$\mathbb{P}$ periodica polytechnica

Mechanical Engineering

$5 4 / 2 ( 2 0 1 0 ) 8 9 \longdiv { 9 4 }$

doi: 10.3311/pp.me.2010-2.05

web: http://www.pp.bme.hu/me

(C) Periodica Polytechnica 2010

RESEARCH ARTICLE

\section{On the microstructure of ceramic hollow microspheres}

\author{
Imre Orbulov / Kornél Májlinger
}

Received 2010-11-31

\begin{abstract}
Metal matrix syntactic foams (MMSFs) are relatively new materials which have increasing interest in the field of aviation and packaging industry. They are metal matrix composites, and their porosity is ensured by the incorporation of ceramic hollow microspheres. In this paper the microstructure of the ceramic hollow microspheres as reinforcing element was investigated. SL150, SLG and SL300 type ceramic microspheres were investigated. They contain various oxides, mainly $\mathrm{Al}_{2} \mathrm{O}_{2}$ and $\mathrm{SiO}_{2}$. Energy dispersive $X$-ray spectroscopy (EDS) maps were recorded from the sections of the microspheres' wall. The results showed that the $\mathrm{Al}_{2} \mathrm{O}_{3}$ and $\mathrm{SiO}_{2}$ distribution was not equal; the $\mathrm{Al}_{2} \mathrm{O}_{3}$ phase was embedded in the surrounding mullite and $\mathrm{Si}_{2}$ phase in the form of needles. EDS along a line in aluminium matrix syntactic foams was carried out in order to investigate the possible reaction between the aluminium matrix and the ceramic microspheres. Due to the uneven distribution of $\mathrm{Al}_{2} \mathrm{O}_{3}$ rich particles, the molten aluminium can reduce the $\mathrm{Si}_{2}$ rich parts of the microspheres and the wall of the microspheres become damaged and degraded. This chemical reaction between the microspheres and the walls can make the infiltration easier, but the resulting mechanical properties will be lower due to the damaged microsphere walls.
\end{abstract}

\section{Keywords}

Metal foam $\cdot$ metal matrix composites $\cdot$ metal matrix syntactic foam $\cdot$ microstructure $\cdot$ interfaces

\section{Imre Orbulov}

\section{Kornél Májlinger}

Budapest University of Technology and Economics,Department of Materials Science and Engineering, Bertalan Lajos street 7. H-1111 Budapest, Hungary

\section{Introduction}

Nowadays metallic foams become more and more important and this is confirmed by the increasing number of papers published on this topic.The "conventional" metallic foams, which contain metallic and gas phase only, have widespread literature. However there are still existing problems for example in accordance with the foaming process of the foams [1,2]. The metallic foams have a special class which satisfies the definition of particle reinforced metal matrix composites also. These are the metal matrix syntactic foams (MMSFs). The first of them was produced in the '90s. The MMSFs have numerous perspective applications as covers, hulls, castings, or in automotive and electromechanical industry sectors because of their high energy absorbing and damping capability. In these porous materials the porosity is ensured by incorporating ceramic hollow microspheres [3]. The microspheres are commercially available and they contain mainly various oxide ceramics [4,5]. The quality of the microspheres has a strong effect on the mechanical and other properties of the foams. The behavior of the foams has been widely studied.

The most important properties of the foams are the compressive strength and the absorbed energy. Wu et al examined the effects of the microballoon size on the compressive strength. They found that smaller microspheres ensure higher compressive strength because they contain fewer flaws in their microstructure, than the larger ones. The damage propagation of the foams was also investigated. The fracture was initialized in the corners of the specimens by the shearing of the microspheres [6]. Rohatgi et al also investigated the size effect of the microspheres, but not only in the view of compressive strength, but in the view of infiltration too. Their measurements showed that the larger microspheres can be infiltrated easier [7]. Palmer et al proved that the larger microspheres contain more porosity in their wall and more flaws in their microstructure, than the smaller ones [8]. The results of the performed upsetting tests were compared to other works on this topic. The conclusions were the same [9,10]. Balch et al performed a special upsetting test. The loading was applied in small steps and after each test X-ray or neutron diffraction measurements were carried out. 
The main aim of the work was to investigate the load transfer from the matrix to the microspheres. They found a chemical reaction between the microspheres and the matrix materials which has detrimental effect on the load transfer and through that on the mechanical properties of the foams [11]. In their previous work Balch et al found that the microspheres have at least the same importance in the syntactic foams than the matrix material. Their fracture strength and the yield strength of the matrix determine the failure stress of the syntactic foams. Therefore the investigation of the microstructure and the quality of the microspheres is very important [9]. Besides the compressive strength other mechanical properties, such as the tensile strength, or the hardness of the syntactic foams were investigated [12, 13]. The sliding behavior of the syntactic foams was also examined because the ceramic microspheres have large hardness and therefore the composite shows better wear behavior, than the pure matrix [14, 15].

As it can be seen in the previous paragraph the quality and chemical composition of the microspheres influence many properties of the syntactic foams. And they also have strong influence during the production of the syntactic foams. The foams are usually produced by mixing technique and gravitational casting or by pressure infiltration. In all cases the contact angle between the ceramic microspheres and the metal matrix has a detrimental effect on the infiltration characteristics and on the threshold pressure (in the case of pressure infiltration)[16-18]. The contact angle is influenced by many parameters and among them the chemical composition and the possible reaction between the reinforcement and the matrix material. Therefore the microspheres should be precisely investigated on the microstructure's scale. The ultimate method for this purpose is scanning electron microscopy and energy dispersive X-ray spectroscopy (EDS). EDS is sensitive to the chemical composition and able to investigate a point, a line or even an area. These possibilities give extremely good opportunities to get detailed information about the microstructure of the microspheres and about the distribution of their constituents. According to the published works mentioned above the main aim of this work was to investigate the microstructure and the distribution of the constituents in ceramic hollow microspheres in order to provide information for metal matrix syntactic foam production and for their expectable mechanical behavior.

\section{Materials and methods}

The investigated materials were SL150, SLG and SL300 type microspheres provided by Envirospheres Ltd. (Australia)[5]. Their main parameters are listed in Tab. 1. The phase composition was determined by X-ray diffraction measurements. For this purpose a Phillips X-Pert type diffractometer with $35 \mathrm{~mA}$ cathode heating current and copper anode $\left(\mathrm{CuK}_{\alpha}, \lambda=0.154186\right.$ $\mathrm{nm}$ ) with $40 \mathrm{kV}$ voltage was used. The rotating speed of the goniometer was 0.04 degree/s. The SEM tests were performed by a Phillips XL-30 type electron microscope equipped with an
EDAX Genesis EDS analyzer. The ceramic microspheres were coated with carbon in order to get a conductive layer on them, but basically they were investigated in as received condition. The excitation was $15 \mathrm{kV}$ and EDS maps were recorded from the surface of the microspheres. Five typical microspheres were investigated from each SL type microsphere group.

Morphological properties and phase constitution of the applied hollow ceramic spheres (provided by the manufacturer, except the size range published in [19] and the chemical composition measured by XRD). Later the microspheres were incorporated in pure aluminium (A199.5) or aluminium-silicon (AlSi12) alloys to create MMSFs. The foams are designated according to their matrix and reinforcement. For example Al-SL150 denotes pure aluminium matrix syntactic foam with SL150 microsphere reinforcement. The volume fraction of the microspheres was maintained at relatively high $(\sim 60 \mathrm{vol} \%)$ level and the production method is described in a previous paper [3]. The density and porosity values of the MMSFs were listed in Tab. 2, while the chemical compositions of the MMSFs are shown in Tab. 2 and Tab. 3Calculated and measured density and porosity values of the MMSFs [3]. In Tab. 2 the theoretical density and particle porosity was calculated from the geometrical parameters of the microspheres. The matrix porosities were calculated as the difference between theoretical and measured density divided by the theoretical density. The negative matrix porosity refers to infiltrated microspheres (the particle porosity should be decreased). However, the values of matrix porosity always remained below $8 \%$, so the infiltration can be qualified as good enough. The values of Tab. 3 were determined XRD measurements described above. Line EDS measurements were carried out on the foams to characterize the elemental distribution at the interfaces, where the hollow microspheres are in contact with the matrix. All EDS line analyses of the elemental distribution were performed on polished surfaces, where the excitation voltage was $15 \mathrm{kV}$. The measurement started from the matrix materials and crossed the wall of the hollow sphere. Thirty points were measured along each line. Each point was excited for $30 \mathrm{~s}$ with $30 \mathrm{~ns}$ dwell time.

\section{Results and discussion}

\subsection{EDS mapping}

For example, Fig. 1 shows typical site from the outer surface of an SL150 type microsphere is shown, while Fig. 2 presents the SEM micrograph from the cross section of a microsphere in A199.5 matrix foam sample.

In both pictures needle-like structures can be clearly observed.They are situated densely and they do not have any distinguished direction. The different gray scale of the needles on the back-scattered electron (BSE) pictures indicates somewhat different chemical composition. The needles are very small, their length is between 5 and $10 \mu \mathrm{m}$, while their diameter is lower than $0.5 \mu \mathrm{m}$. Therefore EDS maps give much more useful results than single EDS spot measurements, because single spots 
Tab. 1. Morphological properties and phase constitution of the applied hollow ceramic spheres (provided by the manufacturer, except the size range published in [19] and the chemical composition measured by XRD)

Tab. 2. Calculated and measured density and porosity values of the MMSFs [3]

Tab. 3. Phases in the aluminium matrix syntactic foams according to XRD measurements (wt\%).

\begin{tabular}{lllllllll}
\hline Type & $\begin{array}{l}\text { Average } \\
\text { diameter } \\
(\mu \mathrm{m})\end{array}$ & $\begin{array}{l}\text { Particle size } \\
\text { range }(95 \%) \\
(\mu \mathrm{m})\end{array}$ & $\begin{array}{l}\text { Specific } \\
\text { surface } \\
\left(\mu \mathrm{m}^{-1}\right)\end{array}$ & $\begin{array}{l}\mathrm{Al}_{2} \mathrm{O}_{3} \\
\mathrm{wt} \%\end{array}$ & $\begin{array}{l}\text { Amorphous } \\
\mathrm{SiO}_{2}\end{array}$ & Mullite & Quartz & Other \\
\hline $\mathrm{SL} 150$ & 100 & $56-183$ & 0.060 & $30-35$ & $45-50$ & 19 & 1 & Bal. \\
$\mathrm{SLG}$ & 130 & $85-233$ & 0.046 & & & & & \\
$\mathrm{SL300}$ & 150 & $101-330$ & 0.040 & & & & & \\
\hline
\end{tabular}

\begin{tabular}{llllll}
\hline \multirow{2}{*}{ Specimen } & Density $\left(\mathrm{gcm}^{-3}\right)$ & \multicolumn{3}{c}{ Porosity $(\%)$} \\
\cline { 2 - 6 } & Theoretical & Measured & Particle & Matrix & Total \\
\hline Al-SL150 & 1.3442 & 1.4273 & 50.9 & -6.2 & 44.7 \\
Al-SLG & 1.3833 & 1.4635 & 49.5 & -5.8 & 43.7 \\
Al-SL300 & 1.4178 & 1.5197 & 48.2 & -7.2 & 41.0 \\
AISi-SL150 & 1.3226 & 1.3076 & 50.9 & 1.1 & 52.0 \\
AISi-SLG & 1.3617 & 1.3340 & 49.5 & 2.0 & 51.5 \\
AISi-SL300 & 1.3962 & 1.3698 & 48.2 & 1.9 & 50.1 \\
\hline
\end{tabular}

\begin{tabular}{lcclllll}
\hline Specimen & $\mathrm{Al}$ & $\mathrm{Si}$ & Mullite & $\left(\alpha-\mathrm{Al}_{2} \mathrm{O}_{3}\right)$ & $\left(\gamma-\mathrm{Al}_{2} \mathrm{O}_{3}\right)$ & Quartz & Amorphous \\
\hline Al-SL150 & 67 & 8 & 11 & 3 & 11 & 0 & 0 \\
AI-SLG & 63 & 6 & 14 & 4 & 11 & 0 & 0 \\
AI-SL300 & 78 & 0 & 11 & 0 & 0 & 0 & 11 \\
AISi-SL150 & 72 & 7 & 13 & 0 & 0 & 0 & 8 \\
AISi-SLG & 72 & 7 & 13 & 0 & 0 & 0 & 8 \\
AISi-SL300 & 72 & 7 & 12 & 0 & 0 & $0.5-1.0$ & 8 \\
\hline
\end{tabular}

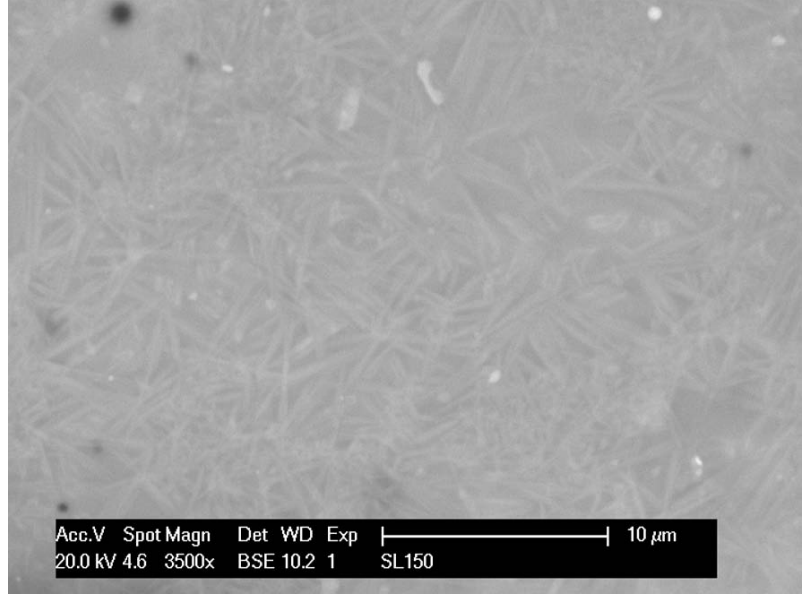

Fig. 1. SEM image from the surface of a SL150 type ceramic hollow microsphere.

can be largely effected by the surrounding matrix.This effect can be decreased or avoided by EDS maps, in which case the results can show the distribution of the elements.Because of this reason EDS map analysis were performed on the surface of the microspheres to get additional information about the element distribution in the microsphere's wall. For this analysis the EDS maps of a SL300 type microsphere are presented as example Fig. 3 .

It is important to emphasize that all of the other microsphere types (SL150 and SLG) showed the same features. Fig. 3 a shows the SEM picture of the investigated surface. The needlelike structure can be again well observed. Fig. 3p shows the distribution of aluminium.It is evident that the needles contain more $\mathrm{Al}$ than the surrounding environment, but $\mathrm{Al}$ can be found everywhere, not only in the needles.From the XRD measurements it is also known that $\mathrm{Al}_{2} \mathrm{O}_{3}$ and $\mathrm{SiO}_{2}$ form mullite

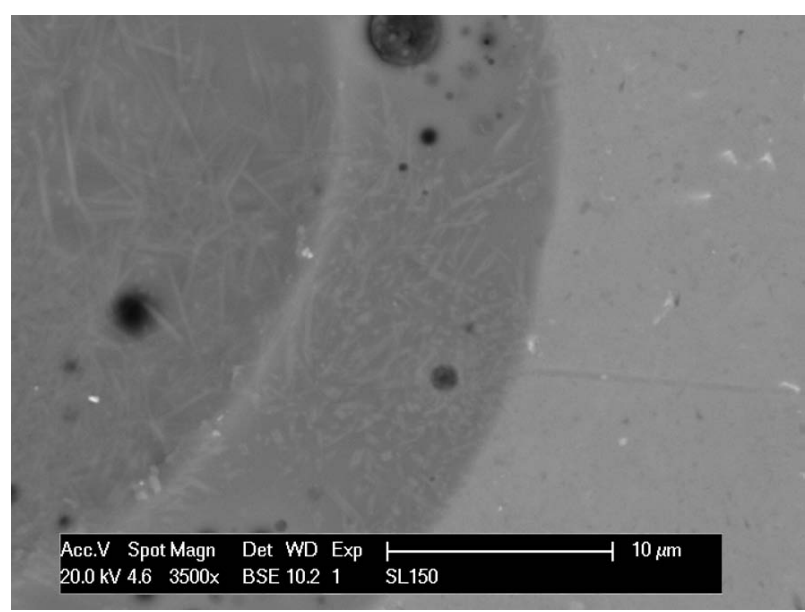

Fig. 2. SEM image for the cross section of a SL150 type ceramic hollow microsphere's wall.
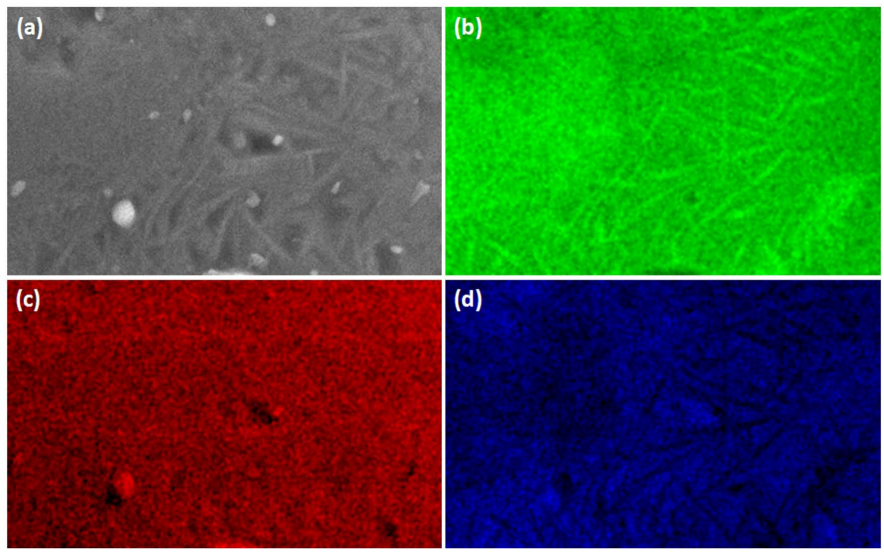

Fig. 3. SEM image from the surface of a SL300 type microsphere (a) and EDS maps for $\mathrm{Al}(\mathrm{b}), \mathrm{O}$ (c) and $\mathrm{Si}(\mathrm{d})$. 
$\left(3 \mathrm{Al}_{2} \mathrm{O}_{3} \cdot 2 \mathrm{SiO}_{2}\right)$, therefore in accordance to the EDS map and Tab. 1 The wall of the microspheres is built up from the mixture of mullite and amorphous $\mathrm{SiO}_{2}$. This means that the distribution of $\mathrm{Al}_{2} \mathrm{O}_{3}$ is uneven, it can be found as the part of mullite in the wall and as $\mathrm{Al}_{2} \mathrm{O}_{3}$ needles embedded in this wall matrix. Fig. 3 d definitely confirms this conclusion by showing the distribution of the silicon. Si can be found everywhere on the surface (mainly amorphous $\mathrm{SiO}_{2}$ mixed with mullite) except in the needles (the needles appear black in this picture). This indicates that, the needles do not contain $\mathrm{Si}$ and therefore they are really $\mathrm{Al}_{2} \mathrm{O}_{3}$ needles. Finally, as it is expected the oxygen distribution (in Fig. 3.) is totally balanced, it is also built in the $\mathrm{Al}_{2} \mathrm{O}_{3}$ and $\mathrm{SiO}_{2}$.

The analyses above show the formation of $\mathrm{Al}_{2} \mathrm{O}_{3}$ rich zones and it indicates the presence of amorphous $\mathrm{SiO}_{2}$ rich zones too. The amorphous $\mathrm{SiO}_{2}$ is undesirable, because - opposite to $\mathrm{Al}_{2} \mathrm{O}_{3}$ and mullite - the chemical stability of $\mathrm{SiO}_{2}$ at elevated temperature is not good enough. During the production of MMSFs the molten aluminium can reduce the $\mathrm{SiO}_{2}$ according to the following chemical reaction:

$$
4 \mathrm{Al}_{\mathrm{liq}}+3 \mathrm{SiO}_{2(\mathrm{sol})} \rightarrow 2 \mathrm{Al}_{3(\mathrm{sol})}+3 \mathrm{Si}_{(\mathrm{sol})}
$$

At first sight this reaction is advantageous, because it forms $\mathrm{Al}_{2} \mathrm{O}_{3}$ (with better properties) from amorphous $\mathrm{SiO}_{2}$. But this is a diffusion controlled reaction and leads to the degradation of the microspheres' wall as it is shown in Fig. 4 a. This indicates drastic drop in the compressive strength and other mechanical properties as it is proved in previous papers [3, 20].
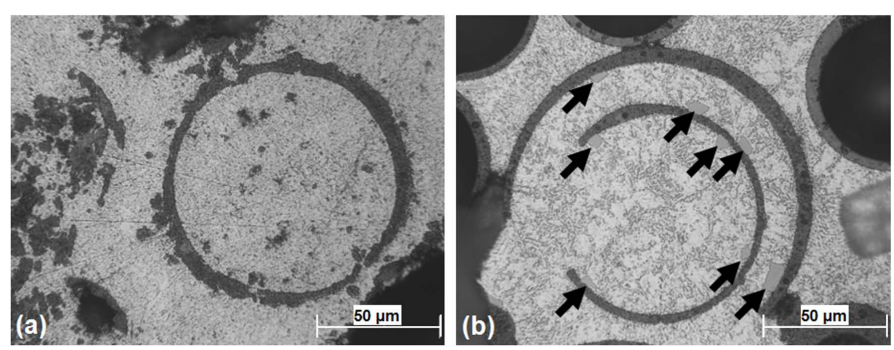

Fig. 4. Micrographs from a damaged (a) and an undamaged (b) microsphere in A199.5 (a) and AlSi12 (b) matrix. The arrows in (b) indicates Si precipitations.

As the XRD results of Tab. 3 shows it, the reaction produces mainly $\gamma-\mathrm{Al}_{2} \mathrm{O}_{3}$ and it took place only in the case of pure aluminium matrix reinforced with SL150 and SL300 type microspheres. In the case of SL300 type microspheres the reaction was suppressed by the lower infiltration temperature. The infiltration temperature had a strong influence on the kinetics of the change reaction. That is why there was no reaction in the case of the Al-SL300 type syntactic foams infiltrated at lower $\left(690^{\circ} \mathrm{C}\right)$ temperature [3]. This indicates that there is a limit relating to the temperature. Above this temperature the reaction is intensive, but below the temperature limit, the reaction will not occur (for details see [3]). The reaction did not take place in the case of AlSi12 matrix material; because the driving force of the diffusion controlled chemical reaction is the Si difference between the molten matrix and the solid microspheres. In the case of AlSi12 metal the large Si content decreased the driving force; the reaction became suppressed and did not take place. Therefore the infiltration temperature (within the normally used ranges) does not have as important role as in the case of A199.5 matrix. The walls of the microspheres remained unharmed as it can be observed in Fig. 4 b. In summary the microspheres built up form $\mathrm{Al}_{2} \mathrm{O}_{3}$ needles embedded in the mixture of amorphous $\mathrm{SiO}_{2}$ and mullite. The chemically reactive molten aluminium can damage the microspheres by reducing their amorphous $\mathrm{SiO}_{2}$ rich parts. This is undesirable in the point of view of mechanical properties.

\subsection{EDS line scans}

After the detailed examination of the microspheres' surfaces, the investigations of the MMSFs were carried out. EDS line measurements were performed on polished specimens perpendicular to the interface layer between the microspheres and the matrix material.The interface layer is very important, because that is responsible for the load transfer from the matrix to the microspheres. The line-scan profiles showed the alternating of chemical elements along the line.The largest advantage of the EDS line method is that this offers a very good opportunity to examine the interface layer and the changes in the hollow microsphere wall in the matrix. Examples for the A199.5 and the AlSi12 matrices are shown in Fig 5 and Fig. 6, respectively.

In Fig. 5, the wall of an SL150 type hollow microsphere can be observed in high magnification BSE image. It can be seen that the outer edge of the wall is not very well defined. This means that the surface of the microsphere is degraded. As mentioned above, the exchange reaction produces $\mathrm{Al}_{2} \mathrm{O}_{3}$, which is advantageous, but not at a price of degrading the hollow microsphere's wall. The diffusion process made a relatively wide interface layer on the outer surface of the hollow microspheres (i.e. from point B to point C). The width of the interface layer was relatively wide $(\sim 6 \mu \mathrm{m})$ and it was measured between the significant changes of the derivation of the fitted curves showing the changing of the Al. Along the interface the $\mathrm{Si}$ and $\mathrm{Al}$ contents increased and decreased, respectively, with a moderate slope. After point $\mathrm{C}$ the $\mathrm{Al}$ content was alternated according to the actual composition of the wall. From point D the measurement is not reliable because of the curvature of the inner surface of the hollow microsphere.

In the case of the AlSi12 matrix the alternating of the Al and Si content - because of the presence of primer Si precipitations in the alloy - can be clearly observed at the beginning of the diagram (Fig. 6). The outer surface was unharmed as the exchange reaction was suppressed by the large $\mathrm{Si}$ content of the matrix. Points $\mathrm{B}$ and $\mathrm{C}$ were very close to each other. This indicates that there is a very narrow (i.e. less than $3 \mu \mathrm{m}$ ) observable interface layer. The sharp, but not totally vertical transition between points $\mathrm{B}$ and $\mathrm{C}$, is a result of the excitation conditions of the electron beam microanalysis. The lack of interface layer on the outer surface confirms that the change reaction was sup- 

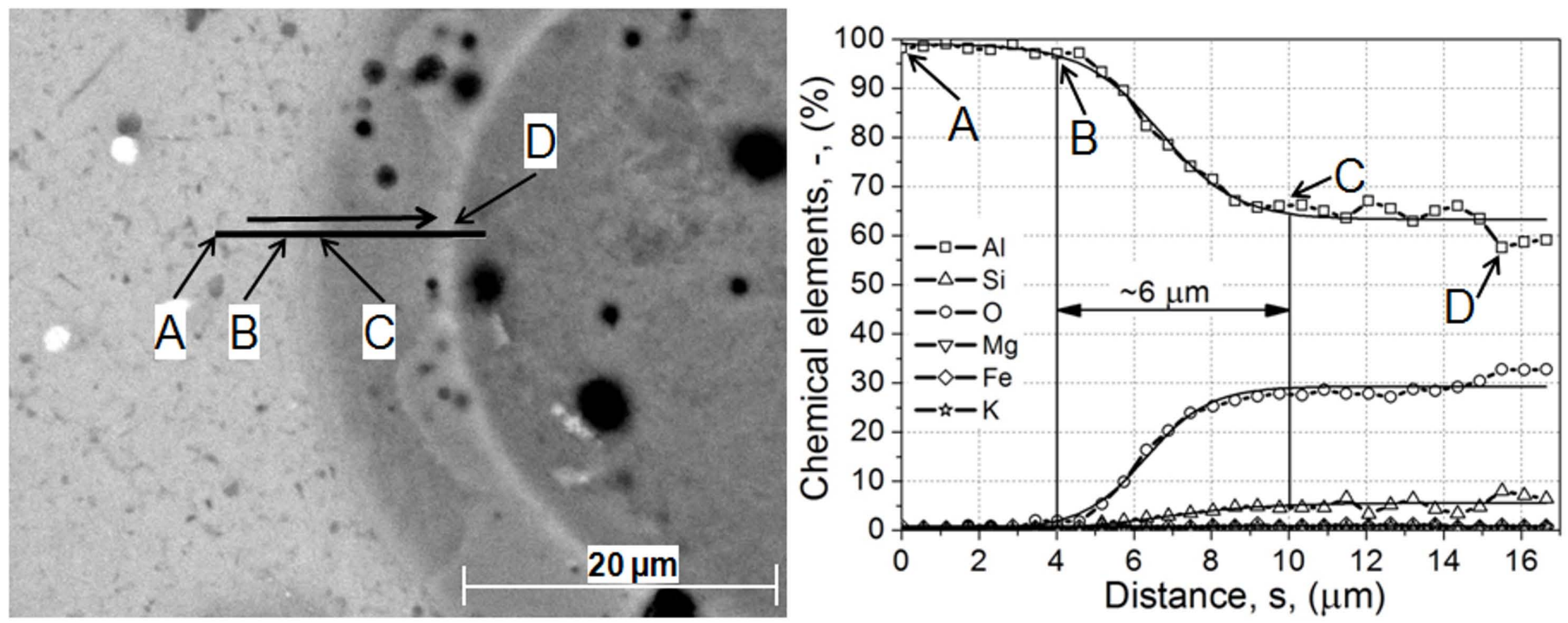

Fig. 5. BSE image and EDS line-scan profiles (with fitted curves) of the Al-SL150 syntactic foams [21].
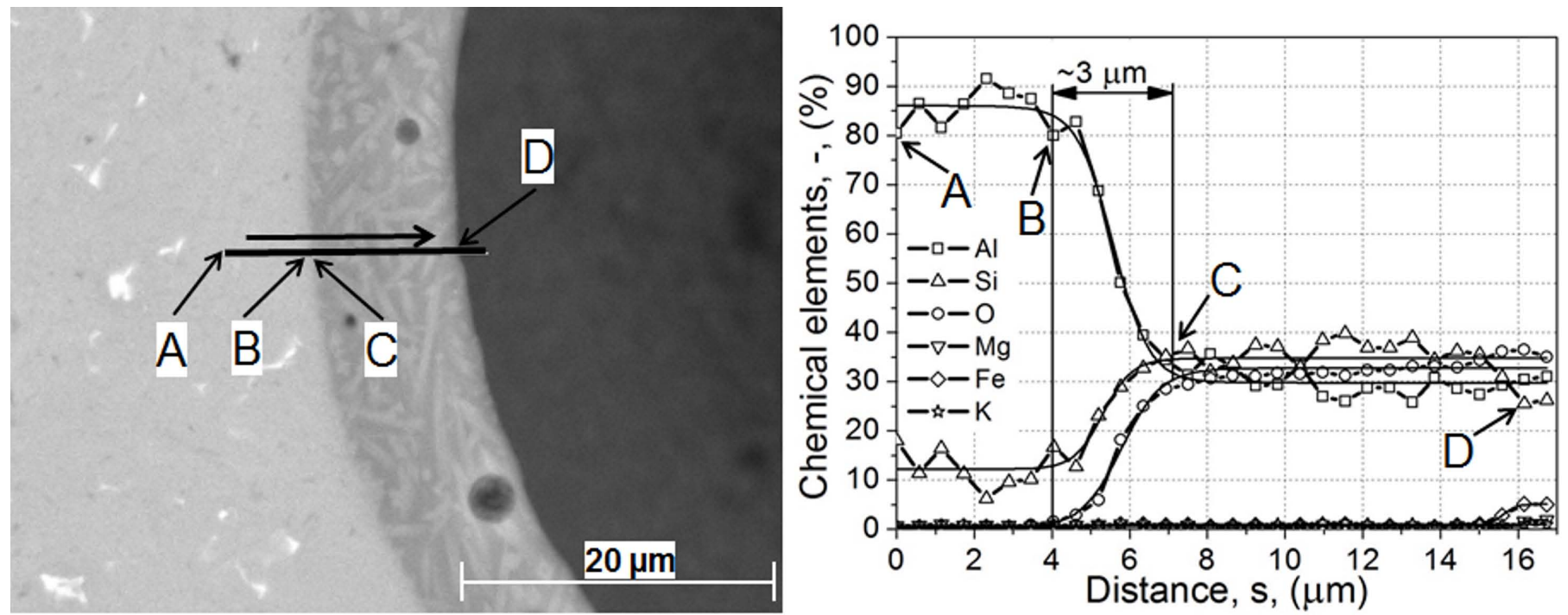

Fig. 6. BSE image and EDS line-scan profiles (with fitted curves) of the Al-SL150 syntactic foams [21.

pressed in these high silicon-containing MMSFs. In the concentrationsensitive BSE image, the lighter needle-like phases can be observed again in the wall of SL150 spheres. According to this a well-defined $\mathrm{Al}$ and $\mathrm{Si}$, alternation occurred in the line of EDS analysis diagram. In the lighter areas, the Si content decreased while the Al content increased. The oxygen content remained constant. This implies that again lighter phases in the wall of hollow microspheres are $\mathrm{Al}_{2} \mathrm{O}_{3}$ particles embedded in $\mathrm{SiO}_{2}$ and mullite matrix. At point $\mathrm{D}$, on the inner side of the hollow microsphere wall, a very narrow $\mathrm{Fe}, \mathrm{Mg}$ and $\mathrm{K}$ rich zone can be observed (originated from the various oxides of the hollow microspheres).

Considering the possibility of chemical reactions between the microspheres and the matrix materials, it is worth mentioning that, the ceramic microspheres can be used as a source of alloying elements in MMSF systems. The appropriate choice and concentration of alloying elements in the wall material or in a surface coating [8] of the microspheres can result in precipitation, grain refinement, and microstructure as per the designed scheme. These alloying elements can enhance the mechanical and/or other properties of the MMSFs. However, there is an effective range of the alloying due to the limited time after infiltration to cooling. If the effective distance between the microspheres is small enough, it is possible to guarantee a homogenous microstructure. If the distance is larger, then the alloying effects are only in the vicinity of the microspheres. In summary EDS line measurements are applicable to investigate the interface layer between the microspheres and the matrix material.The investigations proved the presence of $\mathrm{Al}_{2} \mathrm{O}_{3}$ needles in the wall and the exchange reaction between the $\mathrm{SiO}_{2}$ content of the microsphere and the molten aluminium during the production. The suppressing effect of high Si content was also confirmed. Alloying or coating of the microspheres offers a great opportunity to influence the microstructure and the properties 
of the MMSFs. The authors assume that the microspheres also have an effect on the orientation and size of the matrix materials grains. Therefore a following paper will deal with the electron backscatter diffraction (EBSD) investigation of MMSFs.

\section{Conclusion}

From the results of the above mentioned and discussed EDS and XRD measurements the following conclusions can be drawn:

1 The microstructures of the microspheres, their volume fraction and properties have strong effect on the properties of the MMSFs. SEM and EDS map investigations showed that in the wall of the hollow ceramic microspheres $\mathrm{Al}_{2} \mathrm{O}_{3}$ needles can be found. These needles are packed densely and they are embedded in the mixture of mullite and $\mathrm{SiO}_{2}$.

2 Due to the uneven distribution of $\mathrm{Al}_{2} \mathrm{O}_{3}, \mathrm{SiO}_{2}$ rich zones were formed at the surface of the microspheres. During the MMSF production the molten aluminium chemically attacked these zones and this reductive chemical reaction resulted in severe damage of the microspheres' wall.

3 In the case of A199.5 matrix the reaction was intensive. The driving force of the diffusion controlled reaction was the $\mathrm{Si}$ concentration gradient between the microspheres and the matrix. As for the AlSi12 matrix syntactic foams, the reaction was suppressed by the considerable amount of the $\mathrm{Si}$ in the matrix alloy.

Besides the concrete conclusions above it is worth to mention here that the ceramic microspheres can be used as a source of alloying elements in MMSF systems. The appropriate choice and concentration of alloying element in the wall material or in a surface coating of the microspheres can enhance the properties of the MMSFs.

\section{Acknowledgement}

The Metal Matrix Composites Laboratory is supported by Grant \# GVOP 3.2.1-2004-04-0145/3.0. This paper was supported by the János Bolyai Research Scholarship of the Hungarian Academy of Sciences. The investigations were supported by The Hungarian Research Fund, NKTH-OTKA PD 83687. This work is connected to the scientific program of the "Development of quality-oriented and harmonized $\mathrm{R}+\mathrm{D}+\mathrm{I}$ strategy and functional model at BME" project. This project is supported by the New Hungary Development Plan (Project ID: TÁMOP4.2.1/B-09/1/KMR-2010-0002).

\section{References}

1 Babcsán N, Leitlmeier D, Banhart J, Metal foams-High temperature colloids Part I: Ex situ analysis of metal foams, Colloids and Surf. A: Physicochem Eng Asp, 261, (2005), 123-130.

2 Leitlmeier D, Banhart J, Metal foams-High temperature colloids Part I: Ex situ analysis of metal foams, Colloids and Surf. A: Physicochem Eng Asp, 261, (2005), 123-130.
3 Orbulov I, Dobránszky J, Producing metal matrix syntactic foams by pressure infiltration, Period. Polytech. Mech. Eng, 52, (2008/1), 35-42.

4 Envirospheres Ltd, 15.11.2010, available at WWW.envirospheres.com/ products.asp

5 Sphere Services Inc, 15.11.2010., available at WWW. sphereservices.com

6 Wu G H, Dou Z Y, Sun D L, Jiang L T, Ding B S, He B F, Compression behaviours of cenosphere-pure aluminium syntactic foams, Scripta Mater, 56, (2007), 221-224.

7 Rohatgi P K, Kim J K, Gupta N, Alaraj S, Daoud A, Compressive characteristics of A356/fly ash cenosphere composites synthesized by pressure infiltration technique, Compos. Part. A, 37, (2006), 430-437.

8 Palmer R A, Gao K, Doan T M, Green L, Cavallaro G, Pressure infiltrated syntactic foams - Process development and mechanical properties, Mater. Sci. Eng. A, 464, (2007), 85-92.

9 O'Dwyer J G, Davis G R, Cady C M, Gray G T, Dunand D C, Plasticity and damage in aluminium syntactic foams deformed under dynamic and quasi-static conditions, Mater. Sci. Eng.A, 391, (2005), 408-417.

10 Drury W J, Rickles S A, Sanders T H, Cochran J K, Light weight alloys for aerospace applications, The Minerals Metals and Materials Society, (1998), 311-322.

11 Balch D K, Dunand D C, Load partitioning in aluminum syntactic foams containing ceramic microspheres, Acta Mater, 54, (2006), 1501-1511.

12 Ramachandra M, Radhakrishna K, Synthesis-microstructure-mechanical properties-wear and corrosion behaviour of an Al-Si (12\%)-Flyash metal matrix composite, J. Mater. Sci, 40, (2005), 5989-5997.

13 Ramachandra M, Radhakrishna K, Effect of reinforcement of flyash on sliding wear, slurry erosive wear and corrosive behaviour of aluminium matrix composite, Wear, 262, (2007), 1450-1462.

14 Mondal D P, Das J, Jha N, Dry sliding wear behaviour of aluminium syntactic foam, Mater. Design, 30, (2008), 2563-2568.

15 Rohatgi P K, Guo P K, Mechanism of abrasive wear of Al-Si hypoeutectic alloy containing 5 vol\% fly ash, Tribol. Let, 3, (1997), 339-347.

16 Rohatgi P K, Guo P K, Iksan H, Guo R Q, Borchelt E J, Asthana R, Pressure infiltration technique for synthesis of aluminium-fly ash particulate composite, Mater. Sci.Tech.A, 244, (1998), 22-30.

17 Bárczy T, Kaptay G, Modeling the infiltration of liquid metals into porous ceramics, Mater. Sci. Forum, (2005), 297-302.

18 Trumble $\mathbf{P}$ K, Spontaneous infiltration of non-cylindrical porosity: closepacked spheres, Acta Mater, 46, (1998), 2363-2367.

19 Islam M M, Kim H S, Novel syntactic foams made of ceramic hollow microspheres and starch: theory, structure and properties, J. Mater. Sci, 42, (2007), 6123-6132.

20 Orbulov I N, Németh Á, Dobránszky J, Hardness testing of metal matrix syntactic foams, (Unknown Month May 25). In: Proceedings of 7th International Conference on Mechanical Engineering.

21 Orbulov I N, Dobránszky J, Németh Á, Microstructural characterization of syntactic foams, J. Mater. Sci., 44, (2009), 4013-4019. 